\title{
Organic matter and heavy metals content modeling in sewage sludge treated with reed bed system
}

\author{
Dariusz Boruszko ${ }^{1, *}$, Wojciech Dąbrowski, and Paweł Malinowski \\ ${ }^{1}$ Białystok University of Technology, Faculty of Civil and Environmental Engineering, Department of \\ Technology in Environmental Protection and Engineering, ul. Wiejska 45A, Białystok, Poland
}

\begin{abstract}
The long process of sludge stabilization (7-15 years) remarkably reduces the organic matter content and causes the process of sludge humifaction. This paper presents the results of using low-cost methods of sludge treatment in the wastewater treatment plant located in Zambrow, Podlaskie Province. The results of studies on the organic matter and heavy metals content in sewage sludge after treatment in a reed bed system are presented. The aim of the research was to evaluate and model organic matter and heavy metals concentrations during sewage stabilization in reed bed lagoons. The lowest concentration, below $1.3 \mathrm{mg} / \mathrm{kg} \mathrm{DM}$ of the examined seven heavy metals was mercury $(\mathrm{Hg})$. The highest concentration, exceeding $1300 \mathrm{mg} / \mathrm{kg}$ DM was zinc $(\mathrm{Zn})$. The obtained results for the heavy metals in sewage sludge from the reed bed lagoons in Zambrow show that the average content of the analyzed heavy metals is approximately $1620 \mathrm{mg} / \mathrm{kg} \mathrm{DM}$. The results of the study demonstrate a high efficiency of low-cost methods used in Zambrów WWTP in terms of the quality of the processed sludge. Sewage sludge from the lowest layer of the reed lagoon (12-14 years of dewatering and transformation) is characterized by the lowest organic matter and heavy metals content. The higher a sediment layer lies, i.e. the shorter the time of processing, the higher is the heavy metals content. This indicates a great role of reeds in the accumulation of these compounds.
\end{abstract}

\section{Introduction}

Low-input methods of processing sewage sludge are characterized, first of all, by their simple design, technology and ease of operation. These methods allow using only a limited number of process equipment due to which the consumption of electrical energy is low. Utilization of natural processes occurring in the environment allows maintaining low operation costs [1].

Reed lagoons are successfully used for long-term stabilization and dehydration of sludge from wastewater treatment. They are easy to construct and operate and consume small amounts of energy $[2,3]$. And what is perhaps the most important factor of STRB: any type of sewage sludge of organic kind can be stabilized [4]. For more than thirty years this technology, among others in Denmark, has been applied with success. The initial content of organic matter in the sediment, which is between $50 \%$ and $65 \%$, and low load of the lagoon surface allow for the drainage of sewage sludge to a degree not lower than obtained through using filter presses, that is up to the value of $20 \%-30 \% \mathrm{DM}[3,5,6]$. The content of heavy

\footnotetext{
* Corresponding author: d.boruszko@pb.edu.pl
} 
metals in stabilized sewage sludge is often crucial for the possibility of its use in agriculture. Their excessive content in sewage sludge may be toxic and dangerous to the environment.

Organic matter content in a particular layer can be modeled using statistical analysis. Some heavy metal concentrations also depend on the content of the organic matter and can be modeled afterwards. The obtained models can be used to predict a specified content in a layer given its initial condition and time from its sedimentation.

\section{Material and methods}

\subsection{Sampling}

The samples were collected from 2012 to 2014 at 4 points (from one bed) evenly spaced along the symmetry axes in the 3-meter profile of the sediment fill. Sludge samples from the same layers were mixed and their quality was determined.

Sampling was performed using a special probe to enable the extraction of sewage sludge from the full depth of the lagoon. Samples were averaged and sludge samples from each $0.5 \mathrm{~m}$ section were tested. In 2013 the service of the oldest lagoon was completed after 14 years. The studies reflect the following STBR cycles:

- end of 2012 - after the last 12th year of STBR supply with sewage sludge at full load,

- end of 2013 - after transitional year at STBR supply with sewage sludge at minimum load, - end of 2014 - year after STBR closing.

\subsection{Analytical procedure}

The analysis of the obtained material included examining heavy metal content, dry mass and organic matter, among others. The examinations were carried out in the Department of Technology in Engineering and Environmental Protection laboratory according to the valid norms. Sludge samples were treated with mineralization in $\mathrm{HACH}$ mineralizator with the use of sulphuric acid and hydrogen peroxide mixed with nitric and hydrochloric acid in ratio 1:3. For further analysis mineralizators were filtered through $\mathrm{MN} 616 \mathrm{G}$ paper filter. Determination of cadmium, nickel and total chromium content was done in samples of mineralizators with the use of atomic absorption spectrometer Perkin-Elmer 4100 ZL with transversely heated graphite cuvette and Zeeman-effect background correction. Determination of mercury content was done in samples of mineralizators by means of cold steam technique with the use of atomic absorption spectrometer Perkin-Elmer $4100 \mathrm{ZL}$ equipped in add - on device FIAS-200. Determination of zinc, lead and copper content was done in samples of mineralizators with the use of atomic absorption spectrometer Varian SpectrAA 20 Plus by means of flame atomization. Dry matter and organic matter were determined by using standard methods [7].

\subsection{Statistical model}

Organic matter decay was modeled using first order [8] reaction:

$$
y(t, l)=I(t, l) e^{-k t}
$$

where: $y(t, l)$ - organic matter content in layer $l$ after time $t ; I(t, l)$ - initial organic matter content at the moment of sedimentation in layer, that after time $t$ becomes layer $l$; $k$ - decay rate

By taking logarithm of (1), a linear model is obtained, which is suitable for regression: 


$$
\ln (y(t, l))=[\ln (I(t, l))]+[-k] t
$$

By using sedimentation process specification and year of sampling, it is possible to calculate the year of sediment forming (further called starting year) in a given layer, and the time which has passed since its forming. Due to possible differences in organic matter content during layer formation, additional $0-1$ variable will be included, corresponding to different starting years in a full model:

$$
\begin{gathered}
\ln \left(y\left(t, l_{i}\right)\right)=\left[a_{0}\right]+\sum_{k \in \text { start years }}\left[a_{k}\right] i d_{i, k}+[-k] t \\
i d_{i, k}= \begin{cases}0 & \Leftrightarrow i \neq k \\
1 & \Leftrightarrow i=k\end{cases} \\
\ln \left(I\left(t, l_{i}\right)\right)=a_{0}+a_{\text {start year }(i)} \quad I\left(t, l_{i}\right)=e^{a_{0}+a_{\text {start year }(i)}}
\end{gathered}
$$

where: $i$-index over all samples; $k$-index over start years; $a_{k}$ - coefficients of additional $0-1$ variable.

After initial estimation, variables related to statistically insignificant coefficients (at 5\% significance level) were taken out from model iteratively, until none were left. The final model will be presented in the original form, along with directly calculated coefficients.

Due to the nonlinearity of connection between organic matter and heavy metal content, general additive model (GAM) [9] was used. A dependent variable (heavy metal content) was linearly modeled by smooth function of an independent variable (organic matter content):

$$
z=b_{0}+b_{1} f(y)
$$

where: $z$ - heavy metal concentration; $y$-organic matter content; $f(y)$ - a smooth function; $b_{0}, b_{1}-$ regression terms

Smooth function of an independent variable was estimated using thin-plate regression splines [10] over existing data points. Due to a complicated form of smooth functions, only model coefficients along with a graphical model representation with confidence intervals will be presented. Statistically insignificant coefficients (at $5 \%$ significance level) will be marked out, along with an insufficient linear fit (coefficient of determination less than 0.650 ).

\section{Results and discussion}

The sludge is stabilized and dehydrated. The degree of sludge dehydration is low and ranges from $2.9 \%$ in 2012 to $3.1 \%$ in 2014 . The lowest dry matter content was recorded in the top layer of the vertical profile at $12.6 \%$. The highest content of dry matter, which was $14.5 \%$, was characteristic of sludge that was deposited on the reed lagoon for the longest period of time (the lowest layer in the vertical profile). In the middle section of the vertical profile of sludge at the depth of $1.5-2.0 \mathrm{~m}$, a remarkable reduction in dry matter content was observed: to $10.4 \%$ in 2012 and $13.2 \%$ in 2014 . The dry matter content in STRB in different depths of the vertical profile is an indicator of dehydration. The degree of dehydration is on one hand dependent on the degree of water evaporation from the lagoon surface and, on the other hand, on gravitational concentration and uptake by reed roots [11]. Definitely higher dry matter contents, which were above $29 \%$ in sludge stabilized in STRB, were achieved in studies by Matamoros et al. [12]. The content of organic matter oscillated within a wider range. The lowest organic matter content of $49.0 \%$ DM was recorded in the deepest layer of sludge in 
2014 , i.e. one year after closing the reed lagoon. The highest organic matter values were observed in the highest sludge layer (sludge that was drained and stabilized for the shortest time); these values ranged from $58.1 \% \mathrm{DM}$ to $62.2 \% \mathrm{DM}$. Organic matter accumulated in the sludge over the years undergoes biodegradation and stabilization, leading to a reduction in dry matter content. Similar results of the organic matter reduction by $10 \%-12 \%$ were obtained by Nielsen [6] and in studies conducted in Poland in Darżlubie [2].

The average sum of heavy metals in sludge ranged from $1607.2 \mathrm{mg} / \mathrm{kg} \mathrm{DM}$ in 2014 to $1635.2 \mathrm{mg} / \mathrm{kg} \mathrm{DM}$ in 2012. The highest content, among all the analyzed heavy metals, was recorded for zinc with its mean concentration of $1301.1 \mathrm{mg} / \mathrm{kg} \mathrm{DM}$. Zinc is considered the most essential microelement for plant growth and its very high concentration (above $2500 \mathrm{mg} / \mathrm{kg} \mathrm{DM}$ ) becomes toxic [13]. The lowest content among all of the tested heavy metals was shown by mercury at an average of $1.3 \mathrm{mg} / \mathrm{kg} \mathrm{DM}$. The analysis of heavy metals contents in particular layers (depths) of sewage sludge reveals an increase in zinc and copper levels along with their processing time in the reed lagoon. The highest contents of these metals were recorded at the depth of $1.5 \mathrm{~m}-2.0 \mathrm{~m}$, which amounted to $1412.3 \mathrm{mg} \mathrm{Zn} / \mathrm{kg} \mathrm{DM}$ and $247.0 \mathrm{mg} \mathrm{Cu} / \mathrm{kg} \mathrm{DM}$. The opposite trend was observed in the case of lead and chromium, the overall content of which decreased with the sludge layer depth in the reed lagoon. The highest average loss of the total content was observed in relation to chromium, the concentration of which fell by $26.4 \%$.

\subsection{Model of organic matter and heavy metal content}

Statistical analysis was performed in R environment, version 3.3.0 [14]. For modeling heavy metal content, mgcv package [15] GAM implementation was used.

The final model for organic matter contained only one significant interaction term for the layer from 2012 year. All other samples were modeled using one initial organic matter content. Details of the model are presented in Table 1 and Fig 1.

Table 1. Model for organic matter content.

\begin{tabular}{|c|c|c|}
\hline & estimate & p-value \\
\hline$a_{0}$ & 4.148 & $<0.0001$ \\
\hline$a_{2012}$ & 0.048 & 0.0443 \\
\hline$k$ & 0.019 & $<0.0001$ \\
\hline$R^{2}$ & 0.922 & \\
\hline
\end{tabular}




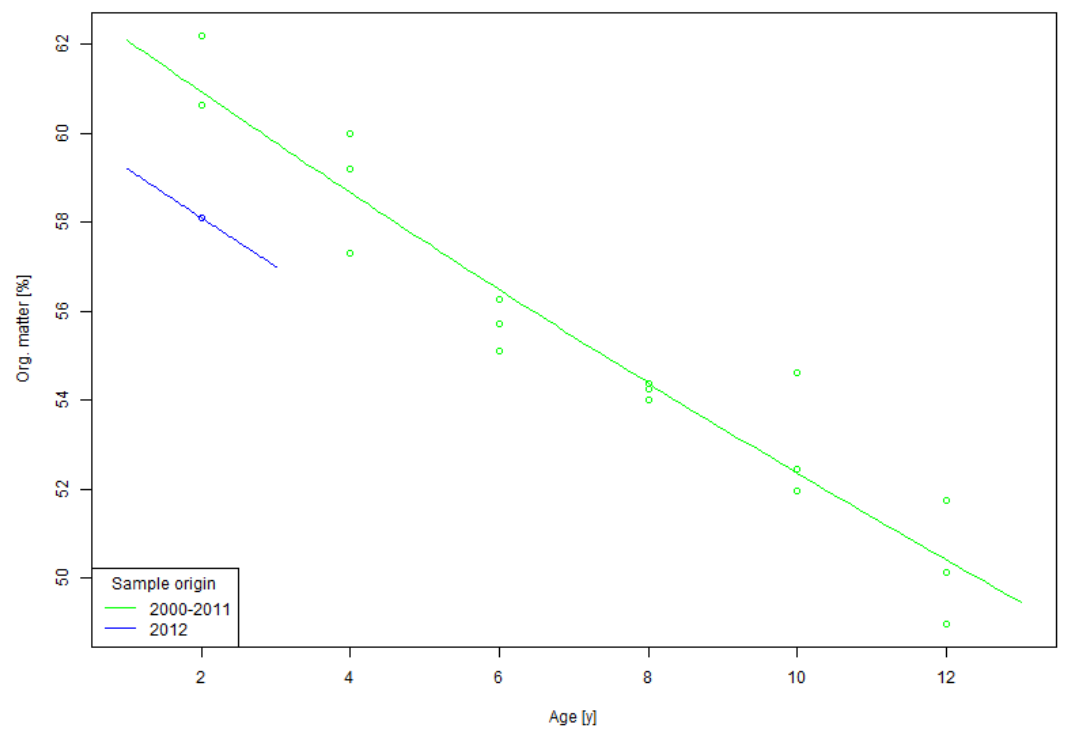

Fig 1. Model for organic matter content.

The obtained model in an explicit form is given by the following equation:

$$
y(t, l)= \begin{cases}63.293 \times e^{-0.019 t} & \Leftrightarrow \text { start year }(l) \neq 2012 \\ 60.348 \times e^{-0.019 t} & \Leftrightarrow \text { start year }(l)=2012\end{cases}
$$

Details of the models for heavy metal concentration are presented in Table 2, where especially low fit or statistically insignificant coefficients are marked red. Fitted models were also presented in Fig 2 with confidence intervals.

Table 2. Heavy metal content model details.

\begin{tabular}{|c|c|c|c|c|c|c|c|c|}
\hline & \multicolumn{2}{|c|}{$\mathbf{P b}$} & \multicolumn{2}{|c|}{$\mathrm{Cr}$} & \multicolumn{2}{|c|}{$\mathrm{Cu}$} & \multicolumn{2}{|c|}{ Cd } \\
\hline & estimate & p-value & estimate & p-value & estimate & p-value & estimate & p-value \\
\hline$b_{0}$ & 30.185 & $<0.0001$ & 53.387 & $<0.0001$ & 210.611 & $<0.0001$ & 2.971 & $<0.0001$ \\
\hline$b_{1}$ & 4.203 & $<0.0001$ & 4.816 & $<0.0001$ & 2.969 & $<0.0001$ & 1.000 & $<0.0001$ \\
\hline \multirow[t]{3}{*}{$R^{2}$} & 0.941 & & 0.927 & & 0.854 & & 0.674 & \\
\hline & \multicolumn{2}{|c|}{$\mathrm{Zn}$} & \multicolumn{2}{|c|}{$\mathrm{Ni}$} & \multicolumn{2}{|c|}{$\mathrm{Hg}$} & & \\
\hline & estimate & p-value & estimate & $\mathrm{p}$-value & estimate & p-value & & \\
\hline$b_{0}$ & 1303.500 & $<0.0001$ & 19.272 & $<0.0001$ & 0.045 & $<0.0001$ & & \\
\hline$b_{1}$ & 3.899 & 0.0061 & 1.000 & 0.0799 & 1.000 & 0.1960 & & \\
\hline$R^{2}$ & 0.688 & & 0.179 & & 0.102 & & & \\
\hline
\end{tabular}



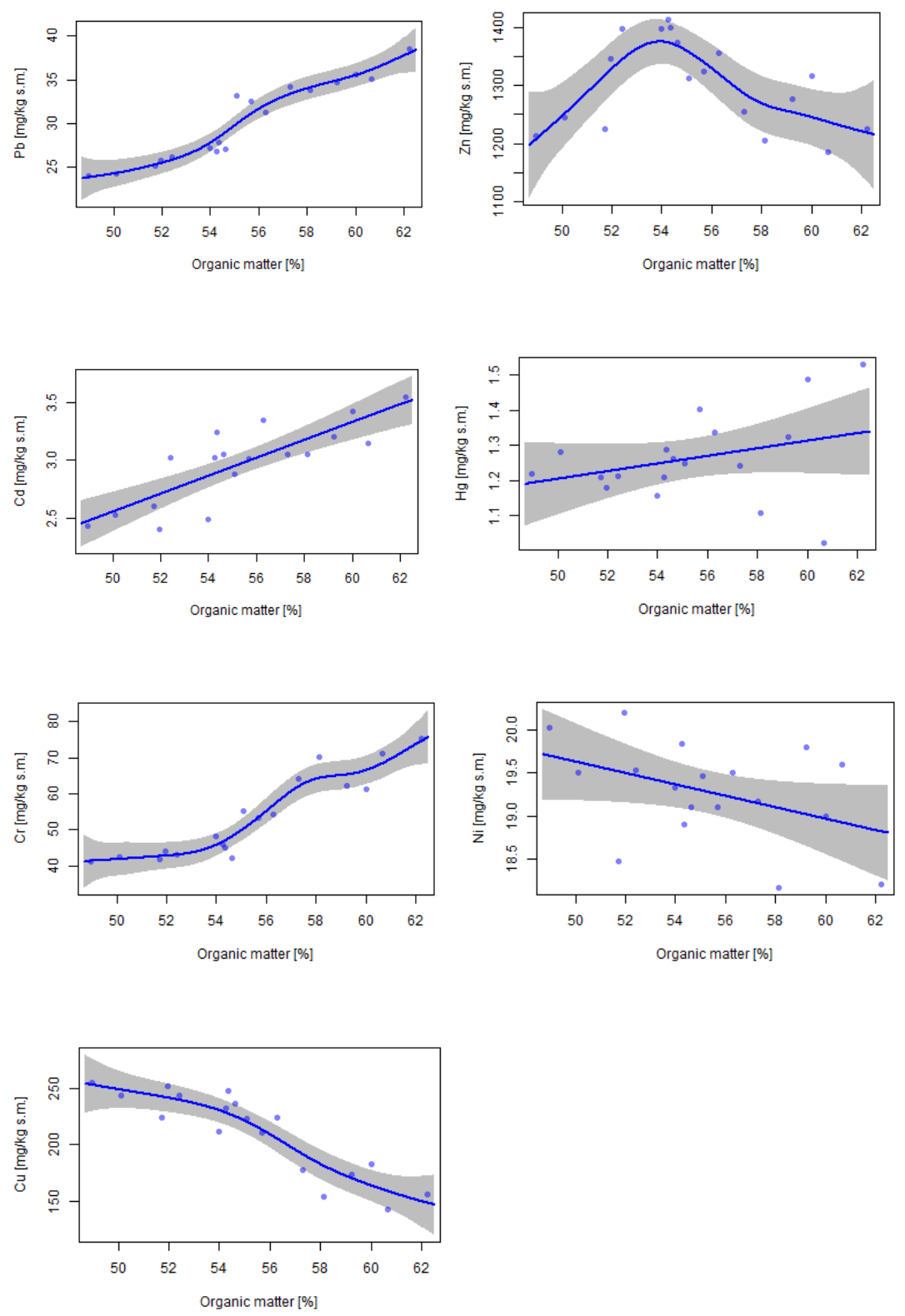

Fig 2. Heavy metal content models.

\section{Conclusions}

From the study results obtained from the long-term stabilization and dehydration of sewage sludge in the reed lagoon, the following conclusions can be drawn: 
1. An increase in dry matter and decline of organic matter occurred in the stabilized sewage sludge.

2. Statistical analysis showed very strong correlations with the organic matter of the sludge layer.

Organic matter content can be modelled with very high approximation using a first-order decay model. The content of many (but not all) heavy metals depends on organic matter concentration. Using obtained models, the content of $\mathrm{Pb}, \mathrm{Cr}, \mathrm{Cu}$ can be estimated with high confidence. The content of other metals like $\mathrm{Cd}$ and $\mathrm{Zn}$ can still be approximated with satisfactory precision using organic matter concentration. In the overall perspective these conclusions mean that the obtained models can be used for estimating heavy metals concentration depending on time which has passed since layer formation.

\section{Acknowledgments}

The study was conducted as a research project S/WBiIŚ/3/2014 in Faculty of Building and Environmental Engineering of BUT and financed by Ministry of Science and Higher Education.

\section{References}

1. D. Boruszko, Eng. Environ. Prot. 13, 1, 29-42 (2010) (in Polish)

2. W. Zwara, H. Obarska-Pempkowiak, Water Sci. Technol. 41, 1, 65-68 (2000)

3. S. Nielsen, E. Peruzzi, C. Macci, S. Doni G. Masciandaro, Stabilisation and mineralization of sludge in reed bed system after 10-20 years of operation. (13th International IWA Specialist Group Conference on Wetland Systems for Water Pollution Control, Perth, Australia, 2012)

4. E. Uggetti, I.Ferrer, E. Llorens E, J. Garcia. Biresour. Technol. 101, 9, 2905-2912 (2010)

5. S. Nielsen, Water Sci. Technol. 48, 5, 101-109 (2003)

6. S. Nielsen, Water Sci. Technol. 63, 5, 941-947 (2011)

7. Standard Methods for the Examination of Water and Wastewater (21th edn, American Public Health Association/American Water Works Association/Water Environment Federation, Washington DC, USA, 2005)

8. K. Kołecka, Long-term changes of the speciation of heavy metals in sewage sludge treatment in reed lagoons (Gdańsk University of Technology, 2007) (in Polish)

9. T. Hastie, R. Tibshirani, Statistical Science 1, 3, 297-318 (1986)

10. S.N. Wood, Journal of the Royal Statistical Society (B) 65, 1, 95-114 (2003)

11. K. Kołecka, H. Obarska-Pempkowiak. Environ. Prot. Eng. 34, 3, 13-20 (2008)

12. V. Matamoros, L.X. Nguyen, C.A. Arias, S. Nielsen, M.M. Laugen, H. Brix, Water Res. 46, 12, 3889-3896 (2012)

13. A. Pathak, M.G. Dastidar, T.R. Sreekrishnan, J. Environ. Manag. 90, 8, 2343- 2353 (2009)

14. $\mathrm{R}$ Core Team, A language and environment for statistical computing (R Foundation for Statistical Computing, Vienna, Austria 2016). https://www.Rproject.org/

15. S.N. Wood, Journal of the Royal Statistical Society (B) 73, 1, 3-36 (2011) 